\title{
LA RECENTRALIZACIÓN Y LOS GOBERNADORES: ¿POR QUÉ NO SIEMPRE SE OPONEN? ANALIZANDO EL CASO DE MÉXICO
}

\author{
Juan C. Olmeda \\ Alejandra Armesto
}

\section{INTRODUCCIÓN}

Si LA DESCENTRALIZACión FUE prominente en la mayor parte del mundo en las décadas de 1980 y 1990, en tiempos más próximos esas reformas se revirtieron, conque comenzaron a observarse políticas de recentralización. Países tan diversos como Brasil, Sudáfrica, Perú, Senegal, Bolivia, Ecuador, Argentina, Venezuela, China, Colombia, Rusia y, más recientemente, México han experimentado esta tendencia, que afectó el balance de poder entre niveles de gobierno. No es sorprendente entonces que una creciente bibliografía sobre recentralización haya comenzado a desarrollarse con el objetivo de explicar este fenómeno.

Una premisa compartida por estos trabajos es que la recentralización es el resultado de interacciones entre actores estratégicos ubicados en diferentes niveles de gobierno, que persiguen sus preferencias en torno a políticas. La mayoría de estos esfuerzos teóricos se han enfocado tanto en entender cuándo las autoridades nacionales están deseosas de recentralizar como en identificar la diversidad de factores que contribuyen a su éxito. Sin embargo, esa discusión asume que las preferencias de los actores son constantes: mientras que los políticos nacionales (por ejemplo, el presidente) siempre estarán a favor de la recentralización como una manera de incrementar el poder, los actores subnacionales (por ejemplo, los gobernadores) siempre se resistirán a estos intentos, 
al percibirlos como una amenaza para sus prerrogativas y el manejo de los recursos bajo su control.

Sin embargo, ¿es verdad que los gobernadores siempre se oponen a la recentralización? Si su posición varía, ¿qué explica estas diferencias? En el presente artículo argumentamos que la bibliografía actual pasa por alto dos fuentes de variación: el tipo de reforma recentralizadora y los intereses de los políticos subnacionales. Cuando estos dos factores se toman en cuenta, no se puede concluir que los actores subnacionales siempre se opongan a recentralizar.

Tomando como punto de partida los trabajos existentes, proponemos un modelo para entender las diferentes posiciones de los políticos subnacionales -los gobernadores- cuando se enfrentan a intentos de recentralización. Argumentamos que su respuesta varía de acuerdo con el tipo de recentralización, así como según los costos y beneficios que los mandatarios estatales asocian a estas medidas. Mientras que se opondrán a una recentralización política, se puede esperar que apoyen o al menos no resistan una recentralización administrativa. Hasta ahora, los trabajos sobre el tema no han provisto una respuesta que explique estos patrones disímiles y con este artículo intentamos llenar este vacío.

Para explorar la plausibilidad de nuestro argumento, analizamos las políticas recientes de recentralización observadas en México durante la presidencia de Peña Nieto (en el cargo desde diciembre de 2012). En particular, mostramos las posiciones divergentes que asumieron los gobernadores respecto -por un ladoa la recentralización administrativa en el plano educativo, que apoyaron, y-por el otro- sobre la recentralización política, a la que se opusieron firmemente. La elección de estos intentos recentralizadores no es casual: se trató de una situación en la que dos reformas distintas fueron implementadas de manera casi simultánea. Esto nos permite realizar una comparación que sirve para controlar otros factores contextuales y evaluar la postura que los mismos gobernadores asumieron frente a dichas políticas. Así podemos concluir, por ejemplo, que si los mismos sujetos se posicionaron de maneras diferentes ante distintas reformas podemos asumir que cuestiones como su pertenencia partidaria no explica dicha actitud. 
El resto del artículo se organiza de la siguiente manera. Una primera sección está dedicada a la teoría; allí se incluye una definición de lo que entendemos por recentralización y una revisión de la bibliografía sobre el tema. La segunda sección propone un modelo analítico para explicar las diversas posiciones de los políticos subnacionales cuando se enfrentan a políticas de recentralización. La sección III aplica nuestro modelo a entender las dinámicas políticas detrás de dos reformas recentralizadoras acontecidas recientemente en México, una administrativa en el área educativa y otra política, en particular en torno a la organización del sistema de control electoral. A lo largo de la sección mostramos las posiciones divergentes que asumieron los gobernadores frente a estas dos reformas y argumentamos que tales diferencias se explican por los diferentes tipos de recentralización que estaban en juego. En una sección final presentamos algunas conclusiones que dan cuenta de la utilidad de nuestro argumento y presentan algunas perspectivas a futuro.

\section{ENTENDIENDO LA RECENTRALIZACIÓN}

Durante las décadas de 1980 y 1990, las políticas de descentralización fueron la regla en los países de América Latina. En la mayoría de los casos, las tendencias descentralizadoras coincidieron tanto con la democratización como con las reformas económicas neoliberales; se propuso inclusive la existencia de fuertes vínculos entre dichos procesos. Una amplia documentación ha analizado extensamente el tema; la mayoría de las explicaciones han entendido la descentralización como el resultado del conflicto político y de las interacciones estratégicas entre actores nacionales y subnacionales. Diferentes trabajos sin embargo pusieron énfasis en factores relacionados con las incentivos territoriales y la secuencia del proceso, ${ }^{1}$ las crisis económicas ${ }^{2} \mathrm{o}$ las cualidades de las reformas neoliberales,

1 T. Falleti, Decentralization and Subnational Politics in Latin America, Nueva York, Cambridge University Press, 2010.

${ }^{2}$ L. González, "Political Power, Fiscal Crises, and Decentralization in Latin 
las características de los partidos políticos ${ }^{3}$ o las carreras políticas, ${ }^{4}$ los cálculos electorales de los líderes políticos nacionales, ${ }^{5}$ motivaciones ideológicas, ${ }^{6}$ la búsqueda de legitimidad, ${ }^{7}$ la competencia electoral, ${ }^{8}$ sólo para mencionar algunos ejemplos. ${ }^{9}$

Más recientemente, las políticas de descentralización parecen haber sido reemplazadas en diversos países por intentos recentralizadores orientados a revertir algunas de las consecuencias de las primeras. En verdad, este fenómeno no parece circunscripto a América Latina y ha sido observado en países tan diversos como Brasil, Sudáfrica, Perú, Senegal, Bolivia, Colombia, Ecuador, Argentina, Venezuela, China, Rusia y México.

En la conceptualización de la recentralización, seguimos a Eaton y Dickovick, quienes la definen como "una serie de cambios designados para revertir reformas que anteriormente expandieron la autonomía subnacional y por lo tanto limitaron las prerrogativas del gobierno nacional". ${ }^{10}$ Algo importante de destacar es

America: Federal Countries in Comparative Perspective (and Some Contrasts with Unitary Cases)", Publius: The Journal of Federalism, vol. 30, núm. 2, 2008, pp. 211-247.

${ }^{3}$ E. Willis, C. Garman y S. Haggard, "The Politics of Decentralization in Latin America”, Latin American Research Review, vol. 34, núm. 1, 1999, pp. 7-56; K. Eaton, "The Link between Political and Fiscal Decentralization in South America", en A. Montero y D. Samuels (eds.), Decentralization and Democracy in Latin America, Notre Dame, Notre Dame University Press, 2004.

${ }^{4}$ Montero y Samuels, op. cit.

${ }^{5}$ K. O'Neill, Decentralizing the State: Elections, Parties, and Local Power in the Andes, Nueva York, Cambridge University Press, 2005.

${ }^{6}$ K. Eaton, "The Centralism of 'Twenty-First-Century Socialism': Recentralising Politics in Venezuela, Ecuador and Bolivia”, Journal of Latin American Studies, vol. 45, núm. 3, 2013, pp. 421-450.

${ }^{7}$ V. Rodríguez, La descentralización en México. De la reforma municipal a Solidaridad y el nuevo federalismo. México, FCE, 1999.

${ }^{8}$ C. Beer, Electoral Competition and Institutional Change in Mexico, Notre Dame, Notre Dame University Press, 2003.

${ }^{9}$ Para una revisión más amplia de las explicaciones sobre las políticas de descentralización, véase Escobar-Lemmon, "Fiscal Decentralization and Federalism in Latin America", Publius: The Journal of Federalism, vol. 31, núm. 4, 2001, pp. 23-41; Montero y Samuels, op. cit.; Falleti, op. cit.

${ }^{10}$ K. Eaton y T. Dickovick, "The Politics of Re-Centralization in Argentina and Brazil”, Latin American Research Review, vol. 39, núm. 1, 2004, p. 94. 
que las políticas recentralizadores parecen tener un punto de inicio claro: son consecuencia de la intención de recuperar poder anteriormente transferido y por lo tanto suponen una vuelta al statu quo previo a la descentralización. ${ }^{11}$ En este sentido, la recentralización implica una reducción del nivel de autonomía subnacional en términos fiscales, administrativos o políticos. En otras palabras, la recentralización debe ser entendida o bien como una reversión de una anterior devolución de poder a autoridades subnacionales electas -ya sea en forma de recursos, autoridad o autonomía en la toma de decisiones-, ${ }^{12}$ o bien como una modificación en el balance de poder en favor del centro en un escenario de postdescentralización.

Dickovick e Eaton han planteado, sin embargo, la necesidad de establecer una diferencia entre dos modos que puede asumir la recentralización, que si bien en ambos casos afectan la autonomía subnacional lo hacen de distintas maneras. ${ }^{13}$ En este sentido, es posible hablar en primer lugar de una "recentralización explícita", basada en cambios normativos e institucionales en la forma en la que se regulan las interacciones intergubernamentales en detrimento de los gobiernos subnacionales. Las redefiniciones de este tipo inevitablemente dan lugar a posicionamientos de las autoridades de los diferentes niveles y en algunos casos a la disputa abierta por hacer avanzar o resistir el proceso. Por otro lado, existe en segundo término una "recentralización sutil" y menos conflictiva, que implica la adopción de políticas que no suponen cambios sustantivos, pero sí un intento por reforzar la posición del centro en las relaciones de poder. ${ }^{14}$ En este último caso, la autonomía subnacional

11 Eaton y Dickovick, "The Politics of Re-Centralization in Argentina and Brazil”, Latin American Research Review, vol. 39, núm. 1, 2004, pp. 90-122; T. Dickovick, Decentralization and Recentralization in the Developing World: Comparative Studies from Africa and Latin America, University Park, The Pennsylvania State University Press, 2011.

12 Dickovick, Decentralization and Recentralization in the Developing World...

${ }^{13}$ T. Dickovick y K. Eaton, "Latin America’s Resurgent Centre: National Government Strategies after Decentralization", The Journal of Development Studies, vol. 49, núm. 11, 2013, pp. 1453-1466.

${ }^{14}$ Entre estas estrategias Dickovick e Eaton (loc. cit.) identifican cuatro tipos: 
no se ve restringida en términos, legales pero sí en su ejercicio. Los casos que se analizan en el presente trabajo se centran fundamentalmente en ejemplos de recentralización del primer tipo.

Tal como ya planteamos en otros trabajos, ${ }^{15}$ las políticas recentralizadoras pueden afectar los tres aspectos que moldean la relación entre los diferentes niveles de gobierno: administrativo, fiscal y político. ${ }^{16}$

En el plano fiscal, el objetivo de las autoridades nacionales al promover la recentralización será recuperar potestad sobre el control de recursos, tanto en términos de gasto como de recaudación. En este sentido, la recentralización fiscal necesariamente implica una redefinición de cómo los recursos son distribuidos entre el centro y las unidades subnacionales. Esto se puede lograr bien reconquistando poder sobre fondos previamente descentralizados a los gobiernos subnacionales o bien creando nuevas fuentes de recaudación no compartidas con otros niveles de gobierno. En relación con la primera, la recentralización se traduce en cambios en el sistema de transferencias con el objetivo de agrandar la porción de recursos bajo control exclusivo del centro o una recentralización de gastos o impuestos previamente transferidos a los gobiernos provinciales. En el caso de la segunda vía, puede mencionarse la creación de nuevos impuestos cuya recaudación es exclusivamente administrada por las autoridades nacionales o el aumento en la discreción del gobierno nacional acerca de cómo se gastan las transferencias.

En el plano administrativo, la recentralización busca volver a concentrar potestades sobre la hechura de políticas públicas y a ejercer influencia tanto en la provisión de servicios como en el diseño y la implementación de programas de gobierno con impacto territorial. Ejemplos pueden ser la creación de programas nacionales con impacto directo sobre la provisión de servicios territoriales, el establecimiento de regulaciones que deben ser cumplimentadas

estrategias de hechura de políticas, estrategias burocráticas, estrategias institucionales y estrategias societales. Estas estrategias son mejor explicadas más adelante.

${ }^{15} \mathrm{~J}$. Olmeda, "El péndulo descentralización-recentralización y su aplicación a la reforma educativa en México", Revista de Relaciones Internacionales, Estrategia y Seguridad, vol. 9, núm. 2, 2014, pp. 143-164.

${ }^{16}$ Falleti, op. cit. 
por las administraciones provinciales en diversas áreas de política pública (como educación, seguridad, salud), la recentralización del pago de la nómina salarial o el control sobre las contrataciones del personal subnacional.

Finalmente, en términos políticos, al recentralizar las autoridades nacionales apuntan a constreñir de alguna manera el espacio de maniobra de los funcionarios locales (ej. gobernadores, alcaldes) o producir "cambios que restringirían la autoridad gubernamental de los funcionarios que han llegado al poder como resultado de las elecciones". ${ }^{17}$ Este tipo de medidas pueden ir desde la suspensión de las elecciones locales y el nombramiento de funcionarios provinciales por decreto presidencial o la creación de regiones autónomas bajo la autoridad directa del gobierno nacional (como hizo Putin en Rusia) hasta estrategias más sutiles tales como cambios en las instituciones electorales para limitar la influencia de las autoridades provinciales en las elecciones locales (como hizo Chávez en Venezuela), el nombramiento de comisionados presidenciales con prerrogativas sobre aspectos particulares de la política local (como hizo Peña Nieto en México), la creación de macro-regiones que medien la relación entre el presidente y las autoridades provinciales, etc.

\section{Acercamientos recientes a la recentralización}

Los procesos concretos de recentralización han concitado el interés de la academia en los últimos años, por lo que los trabajos sobre el tema se han multiplicado. Varios países de América Latina han sido objeto de análisis en este sentido, pero no menor atención ha sido puesta en algunos países de África y en el caso ruso. Desde una perspectiva analítica podemos dividir estos trabajos en tres grandes grupos: 1) aquellos enfocados en los factores que explican la recentralización; 2) los que se concentran en la reacción de los gobiernos

${ }^{17}$ K. Eaton, "Recentralization and the Left Turn in Latin America: Diverging Outcomes in Bolivia, Ecuador, and Venezuela", Comparative Political Studies, vol. 47, núm. 8, 2014, pp. 1130-1157. 
subnacionales frente a los intentos recentralizadores; y 3) los que analizan las estrategias utilizadas por las autoridades nacionales para hacer avanzar su agenda recentralizadora.

Dentro del primer grupo, una línea de trabajo iniciada por el artículo pionero de Eaton y Dickovick ${ }^{18}$ enfocado en Argentina y Brasil pone la atención sobre factores económicos. En particular, se argumenta que las crisis hiperinflacionarias (y la manera en la cual los gobiernos nacionales pudieron exitosamente lidiar con ellas) son predictores de la recentralización. En trabajos posteriores se retoma esta explicación y se concluye que mientras los gobiernos nacionales tienden a descentralizar cuando enfrentan una declinación económica, los presidentes son adeptos a recentralizar una vez que pueden estabilizar la economía después de crisis económica. ${ }^{19}$ González también considera las crisis como eventos centrales para explicar la recentralización: los presidentes tendrán incentivos para recentralizar cuando enfrenten contextos de escasez de recursos fiscales. ${ }^{20}$ Otra visión reciente agrega que lo central es la interacción de la economía con el balance de poder intergubernamental existente: la recentralización ocurrirá o bien cuando una recesión económica tenga lugar en el marco de un arreglo dominado por las autoridades subnacionales (revirtiendo el balance de poder) o cuando un boom económico coincida con un arreglo dominado por las autoridades nacionales (reforzando la distribución de poder existente) ${ }^{21}$

En paralelo, otros trabajos han señalado factores políticos como explicaciones de la recentralización. Por ejemplo, se propone que los presidentes son adeptos a recentralizar cuando perciben que los partidos opositores son más fuertes en el plano Brazil".

18 Eaton y Dickovick, "The Politics of Re-Centralization in Argentina and

${ }^{19}$ Dickovick, Decentralization and Recentralization in the Developing World...

${ }^{20}$ L. González, Presidents, Governors and the Politics of Distribution in Federal Democracies, Nueva York, Routledge, 2016.

${ }^{21}$ J. López Murcia, "The Role of Economic Performance on the Emergence of Recentralization: Colombia, 1994-2014", trabajo presentado en la Conferencia anual de la American Political Science Association, 3-6 de septiembre de 2015 . 
subnacional y que resulta necesario ejercer medidas para combatir su crecimiento. ${ }^{22}$ En paralelo, una serie de investigaciones resalta el rol de las ideas y de quienes las impulsan, más que los intereses materiales de los actores. Por ejemplo, en determinadas circunstancias el discurso recentralizador puede ganar consenso si la fragmentación de poder es percibida como una amenaza y será aceptada aun por aquellos actores (como los gobernadores) que la perciben como contraria a sus intereses. ${ }^{23}$ Asimismo, la recentralización será más probable si las élites políticas que la impulsan ganan poder dentro del aparato estatal. ${ }^{24}$

Un segundo grupo de trabajos ha intentado develar cuáles han sido las respuestas de los gobiernos subnacionales a la recentralización. Por ejemplo, se ha señalado que los gobernadores serán más capaces de resistir la recentralización si logran movilizar a las fuerzas sociales de sus territorios bajo el argumento que dichas políticas pueden poner en peligro su identidad. ${ }^{25}$ Asimismo, se ha argumentado que los gobiernos subnacionales no entrarán en conflicto con el gobierno nacional si perciben que la recentralización se ha convertido en el tipo de política preferida por la mayoría de la población. ${ }^{26}$

Una última línea de trabajo se enfoca en las estrategias y medios utilizados para promover las políticas recentralizadoras. Por ejemplo, Dickovick señala que una parte importante de las políticas recentralizadoras se materializan a través de capas institucionales (institutional layering), ${ }^{27}$ mientras que Dickovick e Eaton desarrollan

${ }^{22}$ Eaton, "The Centralism of 'Twenty-First-Century Socialism'...”.

${ }^{23}$ G. Sharafutdinova, "Gestalt Switch in Russian Federalism? The Decline in Regional Power under Putin”, Comparative Politics, vol. 5, núm. 3, 2013, pp. 357-376.

${ }^{24}$ V. Gel'man, "Leviathan's Return: The Politics of Recentralization in Contemporary Russia”, en C. Ross y A. Campbell (eds.), Federalism and Local Politics in Russia, Nueva York, Routledge, 2009.

${ }^{25}$ Eaton, "The Centralism of 'Twenty-First-Century Socialism'...”.

${ }^{26}$ Sharafutdinova, "Gestalt Switch in Russian Federalism?...".

27 T. Dickovick, "Recentralization in Latin America: Institutional Layering and Presidential Leverage", trabajo presentado en la conferencia anual de la American Political Science Association, 2011. 
una tipología de estrategias observadas en los países latinoamericanos que apuntan a fortalecer el rol del centro en el escenario post-descentralización. ${ }^{28}$ Otros autores han destacado el rol de los partidos políticos en alinear los incentivos de políticos locales y nacionales, ${ }^{29}$ a la vez que un último grupo se ha enfocado en la dimensión discursiva tras las propuestas recentralizadoras y de qué manera dichas políticas son enmarcadas para lograr su legitimación. ${ }^{30}$

Como puede observarse, la discusión sobre recentralización no resulta escasa y plantea diferentes aristas para entender dichos procesos. Sin embargo, la mayoría de los trabajos comparten una visión común ya que se ha acercado a estas políticas desde la perspectiva del centro. Los esfuerzos conceptuales han estado enfocados en entender las razones por las cuales los presidentes deciden recentralizar y las condiciones que garantizan que puedan hacer avanzar su agenda.

${ }^{28}$ Dickovick e Eaton, “Latin America's Resurgent Centre...”. En pocas palabras, cuatro tipos de estrategias son identificadas. Primero, las "estrategias de políticas” hacen referencia a la implementación de programas sociales nacionales enfocados en pasar por alto a las autoridades provinciales y establecer un vínculo directo entre el gobierno nacional y los beneficiarios, lo cual permite a la autoridad nacional reclamar de manera más fácil el crédito por sus acciones. En segundo lugar, las "estrategias burocráticas" hacen referencia al uso de las burocracias nacionales para avanzar hacia los objetivos recentralizadores. Tercero, el gobierno nacional ha llevado adelante "estrategias institucionales" en sus intentos de "usar instituciones nacionales como las cortes electorales, los cuerpos judiciales y el ejército para limitar la autonomía subnacional” (Dickovick e Eaton, op. cit., p. 1454). Finalmente, las "estrategias societales" estuvieron en juego en los casos en los que el gobierno nacional buscó movilizar actores sociales en el nivel subnacional en apoyo de las medidas recentralizadoras.

${ }^{29}$ A. Konitzer y S. Wegren, "Federalism and Political Recentralization in the Russian Federation: United Russia as the Party of Power", Publius: The Journal of Federalism, vol. 36, núm. 4, 2006, pp. 503-522; C. Ross, "Federalism and Electoral Authoritarianism under Putin", Demokratizatsiya: The Journal of Post-Soviet Democratization, vol. 13, núm. 3, 2005, pp. 347-371; G. Sharafutdinova, "Subnational Governance in Russia: How Putin Changed the Contract with His Agents and the Problems It Created for Medvedev", Publius: The Journal of Federalism, vol. 40, núm. 4, 2009, pp. 672-696.

${ }^{30}$ Eaton, "Recentralization and the Left Turn in Latin America..."; Sharafutdinova, "Gestalt Switch in Russian Federalism?...". 
Sorprendentemente, mucho menos ha sido dicho acerca de posibles variaciones en la posición adoptada por los políticos subnacionales frente a las políticas recentralizadoras. En realidad, se asume que estos políticos siempre se opondrán a la recentralización y tratarán de movilizar diferentes recursos con la intención de impedir la efectiva implementación de estas políticas. El trabajo de Sharafutdinova es quizás la única excepción a esta posición dominante, aunque presenta dos grandes debilidades. ${ }^{31}$ Por un lado, al centrarse en la dimensión discursiva explícitamente desdeña lo que tiene que ver con los intereses materiales como fundamento para entender las motivaciones detrás del accionar de los actores políticos. En segundo lugar, el caso que analiza no le permite observar que en un contexto similar las autoridades subnacionales pueden reaccionar de manera diferente frente a diversos tipos de recentralización.

La evidencia empírica parece mostrar no sólo que los políticos subnacionales no siempre se oponen a la recentralización, sino que su posición puede variar de acuerdo al tipo de recentralización que enfrentan: mientras que en algunas ocasiones efectivamente reaccionan en contra de la recentralización, en otros se abstienen de intervenir o incluso la apoyan.

Dado que los esquemas conceptuales que han intentado abordar la recentralización no proveen una explicación para esta variación, en la siguiente sección presentamos un marco teórico alternativo.

II. UN MODELO TEÓRICO ALTERNATIVO: TIPOS DE RECENTRALIZACIÓN Y RESPUESTAS DE LOS POLÍTICOS SUBNACIONALES

Retomando y extendiendo de alguna manera la lógica utilizada por Falleti ${ }^{32}$ para explicar la descentralización, argumentamos que la respuesta de los políticos subnacionales a las iniciativas de recentralización será diferente según el tipo de recentralización que esté

${ }^{31}$ Sharafutdinova, "Gestalt Switch in Russian Federalism?...".

${ }^{32}$ Falleti, op. cit. 
en juego y que la adhesión u oposición de los actores subnacionales a las reformas se derivará del impacto que las mismas tengan sobre sus intereses territoriales, así como de las oportunidades y constreñimientos que impongan los incentivos partidarios.

Los intereses territoriales de los actores políticos están determinados por el nivel del gobierno que representan o gobiernan. ${ }^{33}$ Si los políticos nacionales tienen una visión más general, los subnacionales se concentrarán en sus propios estados o provincias. Por ejemplo, mientras los políticos nacionales privilegian la estabilidad macroeconómica del país, en general, los subnacionales van a preferir maximizar sus ingresos a los fines de poder ampliar la oferta de servicios públicos por los cuales son evaluados, ${ }^{34}$ maximizar su autonomía política y minimizar responsabilidades de provisión de beneficios de política pública sobre los cuales no tienen poder de decisión. Las características estructurales de las jurisdicciones que gobiernan o representan también pueden moldear los intereses territoriales de los políticos subnacionales. Por ejemplo, las preferencias con respecto a las prerrogativas impositivas no son homogéneas para regiones con estructuras económicas diversas. Autoridades subnacionales que gobiernan territorios con economías fuertes y bases impositivas amplias preferirán la descentralización de las potestades tributarias, mientras los gobernantes de regiones pobres favorecerán un sistema impositivo centralizado con fórmulas redistributivas para las transferencias intergubernamentales. ${ }^{35}$ Estos intereses territoriales darán forma a las preferencias de los políticos subnacionales según cada tipo de reforma.

Como ya se dijo, las reformas recentralizadoras pueden clasificarse en administrativas, fiscales y políticas según la esfera de autoridad

${ }^{33}$ Falleti, op. cit.

${ }^{34}$ Karen L. Remmer y Erik Wibbels, "The Subnational Politics of Economic Adjustment: Provincial Politics and Fiscal Performance in Argentina”, Comparative Political Studies, vol. 33, núm. 4, 2000, pp. 419-451.

35 P. Beramendi y A. Diaz-Cayeros, "Distributive Tensions in Developing Federations", trabajo presentado en la conferencia anual de la American Political Science Association, 2008; T. Dragu y J. Rodden, "Representation and Redistribution in Federations", Proceedings of the National Academy of Sciences, vol. 108, núm. 21, 2011, pp. 8601-8604. 
que se pretende remover de los gobiernos subnacionales para ser devuelta al gobierno central. ${ }^{36}$ Lo importante aquí es que cada tipo de reforma recentralizadora propone una combinación particular de costos y beneficios potenciales para los políticos subnacionales frente al statu quo que resulta de las anteriores políticas descentralizadoras. La evaluación de los mismos influirá de manera decidida en la posición que adopten dichos actores.

En el plano administrativo, los potenciales beneficios electorales de proveer servicios públicos descentralizados no siempre compensan los costos económicos y políticos que se deben afrontar; los costos de generar y proveer servicios públicos tienden a ser más altos que los potenciales beneficios. Por ejemplo, bajo el esquema descentralizado, los políticos subnacionales necesitan invertir una porción significativa de sus presupuestos para financiar la provisión de los servicios descentralizados y deben negociar salarios y condiciones laborales con los empleados públicos transferidos. La posibilidad de una recentralización administrativa supone liberar a los gobiernos subnacionales de responsabilidades de oferta de servicios públicos por las que obtienen poco en términos de retornos económicos o electorales. Entonces, podemos esperar que los políticos subnacionales encuentren la recentralización administrativa atractiva.

En el plano fiscal, los políticos subnacionales siempre preferirán incrementar sus ingresos y sus prerrogativas de gasto más que sus responsabilidades de política pública, tales como aquellas transferidas por la descentralización administrativa sin los recursos necesarios. También intentarán evitar asumir potestades tributarias si su ejercicio supone pagar altos costos políticos frente a la población que gobiernan. Bajo esta configuración de intereses territoriales, las reformas recentralizadoras que impliquen la quita de recursos descentralizados avivarán oposición de todos los políticos subnacionales, a la vez que las reformas que recentralicen poderes tributarios serán probablemente preferidas por gobernantes de regiones pobres y rechazadas por aquellos de las más ricas. 
La descentralización en la esfera política representa para los políticos subnacionales beneficios que usualmente exceden a los costos. Primero, los políticos subnacionales que son elegidos popularmente, y por lo tanto no deben su legitimidad a los funcionarios nacionales sino a los electorados locales, están en una situación de autonomía en términos políticos. Segundo, con base en su autonomía los políticos subnacionales pueden ser más proactivos en su relación con otros poderes al nivel estatal, los que incluso pueden llegar a controlar. Por ejemplo, los gobernadores pueden negociar con la legislatura estatal, con las comisiones electorales locales, las cortes estatales. A su debido tiempo, su influencia política puede permitir a los gobernadores permanecer en el poder (en el caso en el que exista reelección) o garantizar el éxito electoral de sus partidos. Además, pueden usar dicho poder para continuar sus carreras políticas en el nivel nacional. ${ }^{37}$ La recentralización política, que cambiaría el statu quo a partir de la reducción del poder político de los funcionarios subnacionales, será entonces percibida por los mismos como una amenaza a su autonomía política y como un constreñimiento potencial a sus carreras futuras. Por lo tanto, es de esperar que los políticos subnacionales, en particular los gobernadores, se opongan fuertemente a cualquier forma de recentralización política.

Sin embargo, las preferencias de los políticos subnacionales con respecto a cada tipo de recentralización no se traducen automáticamente en una oposición o apoyo explícito. La postura pública de los gobernadores frente al gobierno federal se mide según incentivos partidarios. En sistemas políticos centralizados, es decir aquellos en donde los partidos están sumamente centralizados y el control de las carreras políticas está en manos de las élites nacionales en el centro, los políticos subnacionales dependen de la buena voluntad de los líderes nacionales para alcanzar sus objetivos políticos y por consiguiente tienen fuertes incentivos para alinearse con las instancias centrales de los partidos. ${ }^{38}$ En tales contextos, los po-

${ }^{37}$ La experiencia latinoamericana muestra que muchos candidatos presidenciales fueron previamente gobernadores.

38 A. L. Benton, "What Makes Strong Federalism Seem Weak? Fiscal Resour- 
líticos subnacionales oficialistas con preferencias opuestas a la recentralización pueden asumir que enfrentarán represalias si las expresan públicamente. Por el contrario, en sistemas políticos descentralizados, el control de las carreras políticas reside en organizaciones subnacionales de los partidos, por tanto, los políticos subnacionales gozan de altos niveles de autonomía con respecto al poder central. En estos contextos, los políticos subnacionales podrían hacer públicas sus preferencias respecto de cada tipo de recentralización libremente sin temor a represalias desde el centro. Como resultado de la interacción entre intereses territoriales e incentivos partidarios en sistemas centralizados podemos esperar que los políticos subnacionales alineados con el poder central apoyen o acepten las preferencias del centro (aun en contra de sus intereses), y que los políticos de oposición apoyen la recentralización administrativa y se opongan a la recentralización en materia política y fiscal. Por el contrario, en sistemas de partido descentralizados podemos esperar que los políticos subnacionales independientemente de su afinidad partidaria -oficialistas y oposición- expresen las siguientes preferencias: apoyo a la recentralización administrativa y resistencia a la recentralización en la esferas política y fiscal. En este sentido, si la pertenencia partidaria asume un rol importante en sistemas centralizados, este no es el caso cuando hablamos de sistemas descentralizados. La tabla 1 resume el conjunto de resultados esperados.

Si bien en este trabajo nos concentramos en un sistema descentralizado, dejar planteado el marco teórico en sus términos generales nos permitirá a futuro estudiar también dinámicas observadas en sistemas centralizados.

ces and Presidential-Provincial Relations in Argentina”, Publius: The Journal of Federalism, vol. 39, núm. 4, 2009, pp. 651-676; W. Riker, Federalism: Origin, Operation, and Significance, Boston, Little Brown, 1964; E. Wibbels, Federalism and the Market: Intergovernmental Conflict and Economic Reform in the Developing World, Cambridge y Nueva York, Cambridge University Press, 2005. 


\section{TABla 1}

Posición esperada de los gobernadores frente a diferentes reformas recentralizadoras

\begin{tabular}{|c|c|c|c|c|}
\hline \multirow{2}{*}{$\begin{array}{c}\text { Características del } \\
\text { sistema político }\end{array}$} & \multirow{2}{*}{$\begin{array}{c}\text { Pertenencia } \\
\text { partidaria }\end{array}$} & \multicolumn{3}{|c|}{ Tipo de recentralización } \\
\hline & & Administrativa & Política & Fiscal \\
\hline \multirow[t]{2}{*}{ Centralizado } & Oficialista & Aроуо & Aceptación & Aceptación \\
\hline & Opositor & Aроуо & Resistencia & Resistencia \\
\hline \multirow[t]{2}{*}{ Descentralizado } & Oficialista & Aроуо & Resistencia & Resistencia \\
\hline & Opositor & Aроуо & Resistencia & Resistencia \\
\hline
\end{tabular}

Fuente: Elaboración propia.

\section{LA REGENTRALIZACióN Y LOS GOBERNADORES EN MÉXICO}

\section{Por qué analizar la recentralización en México}

Para explorar la plausibilidad de estas conjeturas acerca de las posiciones públicas esperables de los políticos subnacionales frente a las propuestas recentralizadoras, este trabajo compara dos reformas impulsadas en México a partir del año 2012: una recentralización administrativa en el sector educación yuna propuesta de recentralización en el plano político-electoral. La elección de estas dos reformas no es casual y se basa en motivos tanto teóricos como metodológicos. En relación con los primeros, a diferencia de lo acontecido durante los gobiernos de Fox y Calderón, las reformas recentralizadoras propuestas por la administración de Peña Nieto tuvieron un carácter explícito. Es decir, apuntaron a realizar cambios legales para fortalecer la posición del centro y debilitar la autonomía de los estados. En relación con la segunda cuestión, se trata de reformas que afectan de manera diversa el tipo de intereses territoriales afectados y permite explorar si, tal como suponemos, esto determina reacciones divergentes de los gobernadores. Esto nos asegura que exista variación en las variables independiente (tipo de reformas recentralizadoras) y dependiente (posición de los gobernadores) ${ }^{39}$ en un contexto de un

${ }^{39}$ B. Geddes, "How the Cases You Choose Affect the Answers You Get?", Political Analysis, vol. 2, núm. 1, 1990, pp. 131-150. 
sistema político crecientemente descentralizado. Por otro, al tratarse de reformas que se dieron prácticamente de manera paralela, podemos controlar por otros factores contextuales. Una cuestión fundamental es que los mismos gobernadores fueron quienes debieron hacer frente a las mismas. Por lo tanto, si encontramos divergencia en sus posicionamientos podemos descartar que las mismas estén explicadas por sus cualidades personales, su pertenencia partidaria o su relación con el presidente.

Para medir nuestra variable dependiente (posición de los gobernadores) identificamos sus declaraciones públicas respecto a las propuestas recentralizadoras. Con este objetivo, efectuamos una revisión de las versiones en línea al menos un periódico local para cada uno de los 32 estados mexicanos para el periodo 1 de diciembre de 2012- 31 de marzo de 2013 para la reforma educativa y 15 de octubre de 2013-31 de noviembre de 2013 para la reforma política. ${ }^{40}$ En cada caso identificamos aquellos artículos en los que se hacía referencia a declaraciones públicas de los gobernadores sobre las reformas y cada referencia se codificó como: 1) a favor: cuando el gobernador se refiere a la reforma de manera positiva; 2) neutral: cuando el gobernador hace referencia a la reforma sólo para describirla, utilizando un tono neutral; 3) en contra: cuando el gobernador hace referencia a la reforma de manera negativa, enfatizando sus puntos débiles, efectos negativos o dificultades para su implementación. ${ }^{41}$

${ }^{40}$ La lista de los periódicos locales consultados incluye: La Jornada Aguascalientes (Aguascalientes); La Crónica (Baja California); Punto Medio (Campeche); La Voz del Sureste (Chiapas); La Crónica de Chihuahua (Chihuahua); El Diario de Coahuila (Coahuila); Diario de Colima (Colima); Crónica (Distrito Federal); El Siglo de Durango (Durango); Diario Imagen (Estado de México); La Jornada Guerrero (Guerrero); Mural (Jalisco); El Clarín (Michoacán); Periódico Express de Nayarit (Nayarit); El Sur (Oaxaca); El Popular (Puebla); Plaza de Armas (Querétaro); Diario Imagen (Quintana Roo); Línea Directa (Sinaloa); El Imparcial (Sonora); El Correo de Tabasco (Tabasco); La Prensa (Tamaulipas); Jornada Veracruz (Veracruz); Punto Medio (Yucatán); Zacatecas en Imagen (Zacatecas). Se consultó también en periódicos nacionales como El Universal, Reforma y Milenio para complementar la información.

${ }^{41}$ A modo de ejemplo, la siguiente referencia sobre el gobernador de Aguascalientes se calificó como "En contra" de la reforma política: "El gobernador del Estado, Carlos Lozano de la Torre, fijó su postura con respecto a la iniciativa de 
En total se identificaron 156 artículos referidos a la reforma educativa y 69 en relación con la reforma política. En un segundo paso, utilizando esta información, se estimó la posición de cada gobernador y se los categorizó utilizando las mismas etiquetas ("a favor", "neutral", "en contra"). La categoría "ausencia de una posición clara” se incluyó para los casos en los que no se encontraron declaraciones públicas sobre alguna de las reformas.

México es un caso adecuado para analizar las respuestas de los gobernadores por los siguientes motivos. Es una federación -conformada por 31 estados y un Distrito Federal y alrededor de 2500 municipios-; entre los años 1980 y 2000 experimentó procesos de descentralización y democratización, y más recientemente reformas recentralizadoras; y a partir de las últimas décadas los gobernadores han ganado suficiente autonomía como para no enfrentar demasiados constreñimientos a la hora de expresar sus posiciones públicamente.

Como resultado de la descentralización fiscal y la democratización observada en el país durante las últimas décadas del siglo xx, el sistema político también se descentralizó significativamente y los gobernadores de todos los partidos comenzaron a ejercer un importante grado de autonomía en las arenas políticas local y nacional. A nivel local, ganaron un poder significativo para decidir acerca del diseño e implementación de programas gubernamentales en sus territorios; fortalecieron su control sobre las carreras

algunos actores políticos sobre la modificación del Instituto Federal Electoral (IFE) como Instituto Nacional Electoral, sosteniendo que esto sería una clara regresión y contradicción al artículo 40 de la Constitución Política de México". En el siguiente caso, se trata de una declaración neutra: "El Gobernador del Estado, Guillermo Padrés, regresó el documento entregado por el Congreso Local, el cual planteaba observaciones al decreto de reforma electoral. En el documento se incluían modificaciones a la legislación electoral que afectaban procesos que competen al IFE, ambigüedades y se encarecían los procesos electorales”. Por último, esta declaración del gobernador del estado de Campeche se catalogó como "A favor" de la reforma: "La creación del Instituto Nacional Electoral es una de las mejores noticias en materia de concreción de las reformas que se han construido en el país; es una buena noticia porque se fortalecen las instituciones democráticas, nace una nueva institución con más amplios alcances y fortalezas, consideró el gobernador Fernando Ortega Bernés”. 
políticas locales (candidaturas a las legislaturas locales y a las presidencias municipales), y los nombramientos en la burocracia estatal y en la rama local de los partidos, todo lo cual sirvió para situar a los ejecutivos estatales en una posición de fuerza respecto de los congresos locales y los gobiernos municipales. ${ }^{42}$ En la arena política nacional, los gobernadores controlan significativos recursos fiscales -que administran con gran discrecionalidad-, la composición de las listas de representación proporcional y las candidaturas legislativas de mayoría. ${ }^{43}$ Aunque la autonomía de los gobernadores alcanzó su máximo nivel entre 2000 y 2012, durante las dos administraciones panistas de Vicente Fox y Felipe Calderón, el retorno del PRI a la presidencia en 2012 no les quitó poder económico ni político. Los recursos fiscales que reciben a través de transferencias intergubernamentales son asignados por la Cámara de Diputados donde cuentan con aliados leales ${ }^{44}$ y su futuro político no depende de la buena voluntad del presidente. ${ }^{45}$

\section{Antecedentes y contexto general}

En México, la ola descentralizadora acontecida desde los años ochenta supuso una significativa redefinición de los tres aspectos que regulan las interacciones entre niveles de gobierno -administrativos, fiscales y políticos- revirtiendo la concentración del poder en el centro que había caracterizado al federalismo mexicano desde la década de 1930.

42 Yemile Mizrahi, From Martyrdom to Power: The Partido Acción Nacional in Mexico, Notre Dame, University of Notre Dame Press, 2003; Yemile Mizrahi, "Democracia, eficiencia y participación: los dilemas de los gobiernos de oposición en México", Política y Gobierno, vol. 2, núm. 2, 1995, pp. 177-205.

${ }^{43}$ J. Langston, “Governors and 'Their' Deputies: New Legislative Principals in Mexico”, Legislative Studies Quarterly, vol. 35, núm. 2, 2010, pp. 234-258.

44 Guillermo Rosas y Joy Langston, "Gubernatorial Effects on the Voting Behavior of National Legislators”, Journal of Politics, vol. 73, núm. 2, 2011, pp. 477-493. de 2012.

${ }^{45}$ Guillermo Cejudo, "Los gobernadores y el regreso del PRI", Nexos, agosto 
En el aspecto administrativo, nuevas responsabilidades en la provisión de servicios públicos (tales como educación y salud) se asignaron a los gobiernos subnacionales en los años noventa. Al mismo tiempo, en el plano fiscal el entonces presidente Ernesto Zedillo impulsó la creación de un nuevo tipo de transferencias federales condicionadas (las aportaciones, a ser canalizadas a través del Ramo 33), lo cual descentralizó a las autoridades subnacionales una porción importante del gasto social. ${ }^{46}$

En lo político, se determinó que las autoridades locales -hasta entonces nombradas directamente por el presidente- serían electas por la ciudadanía (por ejemplo, el jefe de gobierno del Distrito Federal), se garantizó el reconocimiento a las victorias electorales a los representantes de la oposición en las entidades federativas y se promovió la creación de comisiones o institutos electorales locales a cargo de asegurar comicios limpios y justos.

La tendencia descentralizadora continuó una vez que el PRI perdió la presidencia en el año 2000. En particular durante el gobierno de Fox (2000-2006), los gobernadores de la oposición (a los que luego incluso se unieron los del propio partido del presidente) lograron consolidar su autonomía a partir del incremento de la porción de recursos bajo su control transferidos desde el gobierno federal. Sin embargo, tanto Fox como su sucesor Calderón intentaron resistir la pérdida de poder a partir de la utilización de diferentes estrategias. ${ }^{47}$

Ahora bien, estos presidentes no impulsaron (porque no quisieron o porque no pudieron) una agenda recentralizadora explícita. La situación cambió cuando el PRI reconquistó la presidencia en 2012 y Peña Nieto tomó protesta proponiendo una extensa agenda reformista negociada entre el PRI y los dos principales partidos de oposición (PAN y PRD) en el marco de lo que se conoció con el Pacto por México. En este contexto pareció ganar fuerza la idea de que la descentralización previa no había servido para cumplir sus propias promesas y, por el contrario, resultados negativos se

${ }^{46}$ Falleti, op. cit.; Rodríguez, op. cit.

${ }^{47}$ Para una mejor conceptualización de las mismas véase Dickovick e Eaton, "Latin America's Resurgent Centre...". 
vislumbraban en la mayoría de las esferas. En este sentido, las políticas recentralizadoras se presentaban necesarias como parte de las reformas que México necesitaba.

En lo que sigue nos concentramos en dos áreas en las que la recentralización se intentó materializar en acciones concretas, poniendo particular énfasis a nuestro objeto de atención: la reacción de los gobernadores a dichas medidas. Para considerar la validez de nuestro argumento a la luz de las reformas, primero describimos el statu quo anterior, segundo, analizamos el proceso alrededor de la discusión de la reforma y, finalmente, describimos el resultado.

\section{Recentralización administrativa: el apoyo de los gobernadores}

La recentralización administrativa durante el gobierno de Peña Nieto afectó particularmente al área de educación, uno de los servicios descentralizados en los años noventa.

La provisión descentralizada de educación implicaba serias afectaciones en la asignación de recursos, desde la perspectiva del gobierno federal, y altos costos desde la de los gobernadores. La oferta descentralizada de educación básica estaba afectada por una serie de distorsiones en la asignación de transferencias intergubernamentales desde el gobierno federal hacia los estados. Por ejemplo, la fórmula aplicada desde 2007 en la distribución de las transferencias consideraba, entre otros indicadores, la matrícula escolar, que se evaluaba por medio de un cuestionario respondido por los directores de las escuelas. Esto ofrecía una oportunidad para distorsiones debido a los incentivos de los directores de las escuelas para exagerar el número de estudiantes con el fin de justificar los turnos y posiciones docentes adicionales. Por otro lado, se ha documentado que los gobiernos estatales desviaban recursos a algunas actividades fuera de la ley, como el pago de salarios a los maestros que tenían más de dos posiciones, y que el gobierno federal estaba transfiriendo más recursos a los estados que registraban movilizaciones de maestros más fuertes. ${ }^{48}$

${ }^{48}$ M. Fernández, "From the Streets to the Classrooms: The Politics of Education Spending in Mexico”, tesis doctoral, Duke University, 2012. 
Cuando la descentralización de la educación fue propuesta por el presidente Salinas, los gobernadores anticiparon un aumento de las cargas políticas y administrativas debido a la transferencia de la responsabilidad de los maestros, las escuelas y los estudiantes y temieron cambios en las fórmulas de reparto de ingresos. A pesar de estas fuertes preferencias contra la descentralización, los gobernadores no se opusieron a ella. ${ }^{49}$ Todavía bajo el régimen hegemónico y el sistema de partidos centralizado, los gobernadores del PRI tenían fuertes incentivos partidistas para silenciar su oposición al proyecto del ejecutivo. ${ }^{50}$

Cuando la descentralización tuvo lugar en 1992, la mayoría de los estados administraban sus propios sistemas de educación básica. Sin embargo, las transferencias intergubernamentales de la federación se calculaban anualmente sobre la base de la cantidad de maestros federales previos a la descentralización ajustando por incrementos salariales y de prestaciones sociales que negociaran las autoridades y el sindicato de maestros (el Sindicato Nacional de Trabajadores de la Educación, SNTE). ${ }^{51}$ Cada año, el SNTE desarrollaba un proceso de negociación de aumentos salariales en dos etapas. En primer lugar, negociaban los salarios con el Ejecutivo Federal; luego, cada rama estatal del sindicato negociaba con las autoridades estatales un aumento que en general era superior al que ya había obtenido el SNTE a nivel nacional. Los gobernadores tuvieron que soportar los costos asociados a la equiparación de los salarios y beneficios entre los trabajadores de la educación federales recientemente transferidos y los maestros estatales. Los salarios tenían que elevarse para que coincidieran con cualquiera de los subsistemas que hubiera obtenido el mayor aumento de los salarios. Cuanto más grande era el sistema estatal

${ }^{49}$ M. Grindle, Interests, Institutions, and Reformers: The Politics of Education Decentralization in Mexico, Washington, D. C., Wilson Center, 2002.

${ }^{50}$ Los partidos de oposición gobernaban sólo un estado, Baja California, bajo el mando de Ernesto Ruffo del Pan.

${ }^{51}$ Gustavo Merino, "Federalism and the Policy Process: Using Basic Education as a Test-Case of Descentralization in Mexico", tesis doctoral, Cambridge, Harvard University, 1999. 
de educación antes de la descentralización, más costoso resultaba para el gobierno del estado nivelar los salarios. ${ }^{52}$

En consecuencia, en virtud de los acuerdos de la descentralización, los gobernadores pasaron a ser responsables de proporcionar educación básica; pero, debido a la negociación entre el gobierno federal y el SNTE, no ganaron control sobre la mayor partida del presupuesto de este sector: los salarios de los maestros. Además de los costes económicos, la descentralización de la educación básica implicó costos políticos para los gobernadores. Estos costos derivan de dos fuentes del poder de los sindicatos: influencia en el nombramiento de los profesores, definición de comisionados, control de maestros temporales y venta de plazas; y el nivel de conflicto entre las autoridades estatales y las ramas estatales del SNTE. En 50\% de los estados mexicanos el nombramiento de todos los maestros era controlado por las secciones estatales del sindicato; en el $45 \%$ de los estados, las designaciones eran controladas en un $50 \%$ por la sección estatal del sindicato; y el resto a de las designaciones de profesores se realizaba mediante concursos gestionados por la burocracia estatal de educación. Sólo en el 5\% de los estados, los sindicatos controlaban menos del $50 \%$ de los puestos de maestros en el sector público. ${ }^{53}$

Además, el conflicto entre las autoridades estatales y los maestros era omnipresente. En 30\% de los estados, los desacuerdos entre las autoridades estatales y el sindicato de maestros eran frecuentes y profundos, los cuales se expresaban con marchas, tomas de las instalaciones y suspensión de las actividades escolares. Aun allí donde el nivel de conflicto era bajo existían diferencias entre las autoridades y los sindicatos de maestros. ${ }^{54}$

52 Andere, "Las leyes, la política y la alta política educativa", Cuestiones Constitucionales, núm. 16, enero-junio 2007.

53 J. Álvarez, V. García Moreno y H. Anthony Patrinos, Institutional Effects as Determinants of Learning Outcomes: Exploring State Variations in Mexico, Policy Research Working Paper 4286, 2007.

${ }^{54} \mathrm{El}$ nivel de conflicto o desacuerdo se evaluó según la frecuencia y la gravedad de diferencias entre las autoridades estatales y la sección sindical local desde el año 2000 hasta 2007. La variable fue codificada de la siguiente manera: “(1) existen desacuerdos, pero no son graves (62\% de los estados); (2) los desacuerdos 
Ciertamente, los arreglos descentralizados de educación básica también implicaban algunos beneficios para los gobernadores. Dado que los ciudadanos se preocupan por los servicios básicos -salud, educación, seguridad pública e infraestructura-, los políticos locales pueden obtener beneficios políticos de proveerlos. ${ }^{55}$ Además, dado el peso político del sNTE, los gobernadores utilizaban las negociaciones con los representantes locales del sindicato para ofrecer beneficios especiales a cambio de apoyo político. ${ }^{56}$ Sin embargo, los costos económicos y políticos de la administración de la educación básica, con recursos limitados y fuertes restricciones políticas, superaban crudamente los posibles réditos políticos.

La recentralización en el sector educación consistió en dos medidas principales: la evaluación centralizada de todos los maestros para determinar la contratación y la promoción, y la recentralización de la nómina de los profesores. La primera medida fue una consecuencia directa de la reforma educativa promovida por Peña Nieto en el contexto del Pacto por México y supuso la creación del Instituto Nacional para la Evaluación de la Educación (INEE). La tarea más importante del INEE es examinar a todos los maestros de todo el país con el fin de determinar quiénes de ellos pueden ser contratados o continuar estando en la nómina. El objetivo de esta medida fue recuperar el control de la política educativa del Estado. En palabras de Emilio Chuayffet, secretario de

son frecuentes pero no profundos; que se manifiestan en las declaraciones en los medios de comunicación (8\%); y (3) casi todos los años hay profundos desacuerdos; que se manifiestan en las marchas, haciéndose cargo de las instalaciones y, en muchas ocasiones, la suspensión de las actividades escolares (30\%)" (ibid., p. 11).

${ }^{55}$ Entrevista con el senador y exgobernador of Guanajuato Juan Carlos Romero Hicks (Ciudad de México, 12 de mayo de 2015).

${ }^{56}$ La práctica común desde el momento en que la educación se descentralizó, las negociaciones entre el sindicato y las autoridades de los profesores se llevaban a cabo en dos rondas. En primer lugar, el SNTE negoció con las autoridades nacionales de un salario básico para todos los docentes de todo el país. En una segunda ronda, el SNTE negociaba con cada gobernador condiciones laborales concretas y bonos para los maestros en ese estado en particular (véase Andrés Lajous, "La recentralización de la educación”, Nexos, 28 de febrero 2013. http://redaccion.nexos.com. $\mathrm{mx} / \mathrm{p}=4626)$. 
Educación al momento de aprobar la reforma, la misma aspiraba a "sacudir las conciencias y para volver la regla del sistema educativo con el estado de forma que será el gran mentor de la actual de México y de las mujeres y los hombres en el futuro". ${ }^{57}$

La segunda medida fue aún más aguda ya que implicó la recentralización de la nómina de docentes estatales. El gobierno central la justificó como una forma de promover la eficiencia económica. Desde el punto de vista del secretario de Hacienda, Luis Videgaray, quien fue el principal actor detrás de esta iniciativa, el nuevo esquema permitiría al gobierno nacional tener un mejor control sobre el número de designaciones de maestros, los movimientos en la nómina y los salarios, y así hacer los gastos más transparentes. ${ }^{58}$

Estas dos medidas recentralizadoras restaron un papel importante en la provisión de educación de la esfera de competencias de los gobiernos subnacionales. Sin embargo, y en consonancia con nuestro argumento, la propuesta fue apoyada por la mayoría de los gobernadores de los estados.

Tal como puede observarse en la tabla 2, casi la totalidad de los gobernadores se mostraron a favor de la medida. Dicho apoyo se vio tanto en mandatarios enrolados en el partido oficial como en la oposición.

TABLA 2

Posición de los gobernadores frente a la recentralización administrativa

\begin{tabular}{rlll}
\hline Estado & \multicolumn{1}{c}{ Gobernador } & Partido & Posición \\
\hline Aguascalientes & Carlos Lozano de la Torre & PRI & A favor \\
Baja California & José Guadalupe Osuna Millán & PAN & A favor
\end{tabular}

57 Véase "Discurso Emilio Chuayffet sobre Reforma Educativa", El Universal, 10 de diciembre de 2012. http://www.eluniversal.com.mx/notas/889148.html.

58 Véase Gerardo Hernández, "El largo brazo de Videgaray”, El Zócalo de Saltillo, 8 de octubre de 2013. http://www.zocalo.com.mx/seccion/opinion-articulo/ el-largo-brazo-de-videgaray-1381217575. 
TABLA 2 (concluye)

\begin{tabular}{|c|c|c|c|}
\hline Estado & Gobernador & Partido & Posición \\
\hline Baja California Sur & Marcos Alberto Covarrubias Villaseñor & PAN & A favor \\
\hline Campeche & Fernando Ortega Bernés & PRI & A favor \\
\hline Chiapas & Manuel Velasco Coello & PVEM & A favor \\
\hline Chihuahua & César Duarte Jáquez & PRI & A favor \\
\hline Coahuila & Rubén Moreira Valdez & PRI & A favor \\
\hline Colima & Mario Anguiano Moreno & PRI & A favor \\
\hline Distrito Federal & Miguel Ángel Mancera & PRD & Neutral \\
\hline Durango & Jorge Herrera Caldera & PRI & A favor \\
\hline Estado de México & Eruviel Ávila Villegas & PRI & A favor \\
\hline Guanajuato & Miguel Márquez Márquez & PAN & A favor \\
\hline Guerrero & Ángel Aguirre Rivero & PRI & A favor \\
\hline Hidalgo & José Francisco Olvera Ruíz & PRI & A favor \\
\hline Jalisco & Aristóteles Sandoval & PRI & A favor \\
\hline Michoacán & Fausto Vallejo Figureoa & PRI & A favor \\
\hline Morelos & Graco Ramírez & PRD & A favor \\
\hline Nayarit & Roberto Sandoval Castañeda & PRI & A favor \\
\hline Nuevo León & Rodrigo Medina & PRI & A favor \\
\hline Oaxaca & Gabino Cué & MC & A favor \\
\hline Puebla & Rafael Moreno Valle & PAN & A favor \\
\hline Querétaro & José Calzada Rivorosa & PRI & A favor \\
\hline Quintana Roo & Roberto Borge Angulo & PRI & A favor \\
\hline San Luis Potosí & Fernando Toranzo Fernández & PRI & A favor \\
\hline Sinaloa & Mario López Valdez & PAN & A favor \\
\hline Sonora & Guillermo Padrés Elías & PAN & A favor \\
\hline Tabasco & Arturo Núñez Jiménez & PRD & A favor \\
\hline Tamaulipas & Egidio Torre Cantú & PRI & A favor \\
\hline Tlaxcala & Mariano González Zarur & PRI & A favor \\
\hline Veracruz & Javier Duarte de Ochoa & PRI & A favor \\
\hline Yucatán & Rolando Zapata Bello & PRI & Neutral \\
\hline Zacatecas & Miguel Alonso Reyes & PRI & Neutral \\
\hline
\end{tabular}

Fuente: Elaboración propia. 
Los mandatarios estatales tenían motivaciones económicas y políticas para apoyar la recentralización administrativa de la educación básica. Las motivaciones económicas tienen sus raíces en los mismos intereses territoriales que los hicieron rechazar la descentralización administrativa en 1992. Algunos de estos gobernantes, se refirieron explícitamente a las deficiencias de la descentralización como una motivación para apoyar recentralización. Por ejemplo, Graco Ramírez, político del opositor Partido de la Revolución Democrática (PRD) y gobernador del estado de Morelos, señaló cuatro factores que impidieron a los gobiernos estatales administrar adecuadamente el sector de la educación: las transferencias intergubernamentales desde el gobierno federal insuficientes, la movilización de los maestros a cambio de prebendas políticas en época de elecciones, el control de los puestos docentes por las secciones locales del sindicato de maestros y la fusión incompleta de los antiguos sistemas de educación estatales y federales. Más crudamente, Gabino Cué, gobernador de Oaxaca, destacó que la centralización de la nómina de los docentes implicaría "levantar la presión" que ejercen las secciones locales de los sindicatos de docentes, que en muchos casos habían convertido a los gobernadores en sus rehenes. ${ }^{59}$

En resumen, cuando el presidente Peña Nieto propuso la recentralización administrativa de la educación básica, el gobierno federal estaba apuntando a recuperar el control sobre la política de educación, que en el régimen descentralizado había sido debilitado por la fuerte influencia del poderoso sindicato de maestros. Aunque la reforma propuso sacar la administración de los recursos económicos y el poder de contratar y despedir de las atribuciones de los gobiernos estatales, los gobernadores no sólo no se resistieron a la reforma, sino que incluso expresaron explícitamente su apoyo. El statu quo descentralizado implicaba costos económicos y políticos significativos para ellos; y sin restricciones

${ }^{59}$ Patricia Briseño y Rolando Aguilar, "Gobernadores apoyan centralizar los pagos”, Excélsior, 11 de septiembre de 2013; y Jorge Ramos y Leticia Robles de la Rosa, "Recentralizan nómina de SEP; proponen dar medicinas "en especie" a estados", Excélsior, 2 de octubre de 2013. 
partidistas fueron capaces de declarar públicamente sus preferencias sinceras en favor de recentralización.

\section{Recentralización política: la oposición de los gobernadores}

En el ámbito político, el intento recentralizador más explícito apuntó a la creación del Instituto Nacional Electoral (INE), que reemplazaría al bien establecido Instituto Federal Electoral (IFE) ${ }^{60}$ y a la desaparición de los institutos electorales locales.

La propuesta, impulsada originalmente por el PAN y negociada luego con el presidente, formaba parte de una reforma política y electoral más ambiciosa (finalmente aprobada con modificaciones por el Senado, la Cámara de Diputados y 18 congresos locales entre finales de 2013 y comienzos de 2014 y promulgada por orden presidencial en febrero de 2014) que también incluyó la re-elección de diputados y senadores, permitió las candidaturas independientes, estableció el requisito de la paridad de género en la selección de candidatos para el Congreso Nacional, y estipuló nuevas causas de nulidad de las contiendas electorales, etc. ${ }^{61}$

El statu quo anterior al intento recentralizador era favorable para los gobernadores ya que suponía la convivencia del IFE, a cargo de la organización y supervisión de las elecciones federales (es decir, los diputados federales, senadores, presidentes) y treinta y dos institutos electorales estatales (uno para cada estado de México) a cargo de organizar y controlar las elecciones locales (es decir, gobernadores, diputados locales, alcaldes). Los consejeros que formaban parte del órgano de gobierno del IFE eran elegidos por el Congreso mexicano, mientras que aquellos de los institutos estatales lo

${ }^{60}$ Algunos autores consideran que el rol del IFE en la creación de condiciones equitativas para la competencia electoral fue crucial para hacer posible la alternancia en el poder en la elección presidencial del año 2000 (véase por ejemplo: Merino, La transición votada, México, FCE, 2003.

${ }^{61}$ Véase, para un extenso análisis de los cambios incluidos en la reforma, R. Torres Ruiz, "México y su nueva reforma político electoral", Revista Mexicana de Estudios Electorales, núm. 4, 2014, pp. 119-159. 
eran por las legislaturas locales. ${ }^{62}$ En este contexto los gobernadores, especialmente en casos de gobierno unificado, ejercían una influencia importante en la selección de consejeros estatales y, como resultado, intervenían en la acción de los institutos electorales estatales para sesgar las elecciones locales a favor de los candidatos de su partido. ${ }^{63} \mathrm{Si}$ bien no existen demasiados trabajos sistemáticos sobre el tema, un estudio realizado por Méndez de $\operatorname{Hoyos}^{64}$ sobre dichos institutos encontró que en al menos 10 de los 32 la influencia de los gobernadores era alta mientras que en una evaluación del diario nacional Reforma se argumentó que en 28 de los 32 institutos electorales del consejo general tenía una composición que estaba cerca de los intereses de los mandatarios estatales. ${ }^{65}$

La propuesta recentralizadora inicial -y en particular el planteamiento de eliminar los institutos electorales locales y la transferencia de sus responsabilidades a una única autoridad electoral de carácter nacional- fue entonces percibida por los gobernadores como una amenaza a su poder dados los altos costos que les implicaría. ${ }^{66}$ Dicha propuesta se incluyó en el Pacto por México (compromiso 5.3) ${ }^{67}$

62 En 2013, los partidos de los gobernadores controlaban la mayoría de los escaños en 20 de las 32 legislaturas locales. Véase "Gobernadores: poder indomable", Reforma, 10 de noviembre de 2013.

63 Torres Ruiz, op. cit.; también: "Inaplazable Reforma Política ante control de los gobernadores en comicios: PAN”, en Radio Fórmula, 3 de octubre de 2013, http:/ / www.radioformula.com.mx/notas.asp?Idn=359327

${ }^{64}$ Irma Méndez de Hoyos, "Los órganos de administración electoral y la calidad de las elecciones locales en México: un análisis de los institutos electorales locales”, en Irma Méndez de Hoyos y Nicolás Loza (coords.), Instituciones electorales, opinión pública y poderes políticos locales en México, México, Flacso, 2013.

${ }^{65}$ Véase "Gobernadores: poder indomable", Reforma, 10 de noviembre de 2013.

${ }^{66}$ Véase http:/ / www.pan.org.mx/blog/2013/05/15/anuncia-pan-propuestapara-conformar-al-ine/. El presidente del PAN, Gustavo Madero, explícitamente afirmó que la reforma política y electoral era una manera de "atar las manos de los gobernadores" con respecto a los temas electorales. Véase, "PAN pide amarrar las manos a gobernadores con reforma política", ElEconomista, 11 de noviembre de 2013, http:/ / eleconomista.com.mx/sociedad/2013/11/11/pan-pide-amarrarlas-manos-gobernadores-reforma-politica

${ }^{67}$ Los partidos acordaron el compromiso de "Crear una autoridad electoral nacional y una legislación electoral nacional a cargo de nacionales, estatales y municipales". Consúltese "Pacto por México", http://pactopormexico.org/. 
y se plasmó en un proyecto de ley presentado por legisladores del PAN el 24 de septiembre de 2013.

Tal como adelantamos en nuestras previsiones teóricas, los gobernadores reaccionaron activamente contra este intento. ${ }^{68} \mathrm{La}$ tabla 3 muestra que aproximadamente la mitad explícitamente se declaró en contra. Lo interesante es que este grupo incluyó a prominentes gobernadores de los tres partidos principales; estos mismos se habían mostrado previamente a favor de la recentralización administrativa.

\section{TABLA 3}

Posición de los gobernadores frente a recentralización política

\begin{tabular}{|c|c|c|c|}
\hline Estado & Gobernador & $\begin{array}{l}\text { Partido } \\
\text { Gobernador }\end{array}$ & Política \\
\hline Aguascalientes & Carlos Lozano de la Torre & PRI & En contra \\
\hline Baja California & José Guadalupe Osuna Millán & PAN & Sin posición clara \\
\hline Baja California Sur & $\begin{array}{l}\text { Marcos Alberto Covarrubias } \\
\text { Villaseñor }\end{array}$ & PAN & Sin posición clara \\
\hline Campeche & Fernando Ortega Bernés & PRI & En contra \\
\hline Chiapas & Manuel Velasco Coello & PVEM & Sin posición clara \\
\hline Chihuahua & César Duarte Jáquez & PRI & En contra \\
\hline Coahuila & Rubén Moreira Valdez & PRI & En contra \\
\hline Colima & Mario Anguiano Moreno & PRI & Sin posición clara \\
\hline Distrto Federal & Miguel Ángel Mancera & PRD & En contra \\
\hline Durango & Jorge Herrera Caldera & PRI & En contra \\
\hline Estado de México & Eruviel Ávila Villegas & PRI & En contra \\
\hline Guanajuato & Miguel Márquez Márquez & PAN & En contra \\
\hline Guerrero & Ángel Aguirre Rivero & PRI & Sin posición clara \\
\hline Hidalgo & José Francisco Olvera Ruíz & PRI & En contra \\
\hline Jalisco & Aristóteles Sandoval & PRI & En contra \\
\hline Michoacán & Fausto Vallejo Figureoa & PRI & Sin posición clara \\
\hline Morelos & Graco Ramírez & PRD & Sin posición clara \\
\hline Nayarit & Roberto Sandoval Castañeda & PRI & Sin posición clara \\
\hline
\end{tabular}

${ }^{68}$ Torres Ruiz, op. cit. 
TABLA 3 (concluye)

\begin{tabular}{llll}
\hline \multicolumn{1}{c}{ Estado } & \multicolumn{1}{c}{ Gobernador } & Partido & \\
\hline Nuevo León & Rodrigo Medina & PRI & En contrática \\
Oaxaca & Gabino Cue & MC & Sin posición clara \\
Puebla & Rafael Moreno Valle & PAN & Neutral \\
Querétaro & José Calzada Rivorosa & PRI & Neutral \\
Quintana Roo & Roberto Borge Angulo & PRI & En contra \\
San Luis Potosí & Fernando Toranzo Fernández & PRI & En contra \\
Sinaloa & Mario López Valdez & PAN & A favor \\
Sonora & Guillermo Padrés Elías & PAN & Neutral \\
Tabasco & Arturo Nuñez Jimenez & PRD & A favor \\
Tamaulipas & Egidio Torre Cantú & PRI & Sin posición clara \\
Tlaxcala & Mariano González Zarur & PRI & A favor \\
Veracruz & Javier Duarte de Ochoa & PRI & Sin posición clara \\
Yucatán & Rolando Zapata Bello & PRI & Sin posición clara \\
Zacatecas & Miguel Alonso Reyes & PRI & En contra \\
\hline
\end{tabular}

Fuente: Elaboración propia.

En este grupo se encontraban por ejemplo gobernadores prominentes como Miguel Ángel Mancera (jefe de gobierno de la Ciudad de México-PRD), Eruviel Ávila (gobernador del estado de México-PRI) o Gabriel Márquez (gobernador de Guanajuato-PAN), quienes en varias ocasiones manifestaron que la eliminación de los institutos electorales estatales constituía una violación a la autonomía subnacional. ${ }^{69}$

En el plano nacional, diferentes funcionarios dieron cuenta de esta reacción contra el intento recentralizador. El senador panista Javier Corral, por ejemplo, denunció que los gobernadores estaban tratando de bloquear la reforma propuesta; y Guadalupe Acosta Naranjo, quien era el secretario técnico del Consejo a cargo del Pacto por México en representación del PRD, sostuvo que 2013.

69 Veáse "Gobernadores: poder indomable", Reforma, 10 de noviembre de 
los gobernadores no querían que una autoridad nacional auditara las elecciones estatales y no estaban dispuestos a renunciar a ejercer influencia en el nombramiento de los consejeros electorales estatales. ${ }^{70}$ El presidente del PAN, Gustavo Madero, también subrayó la oposición de los gobernadores, argumentando que querían bloquear las negociaciones de todo el Pacto por México con la intención de detener la reforma política. ${ }^{71}$

El rechazo de los gobernadores no fue en vano: consiguió que el 18 de noviembre de 2013 se anunciara que se eliminaba del proyecto de reforma la abolición de los institutos locales. ${ }^{72}$ Ciertamente, al creado INE se le otorgaron prerrogativas importantes en la organización y supervisión de las elecciones locales, pero sólo en el caso que se produzcan "circunstancias extraordinarias". ${ }^{73}$ De no existir estas condiciones, esta facultad queda bajo responsabilidad de los Órganos Públicos Locales Electorales (OPLE) (nueva denominación de los institutos electorales locales). Por otro lado, la reforma efectivamente aprobada estableció que los miembros de los

${ }^{70}$ Veáse "Gobernadores presionan para armar una reforma política a modo: Corral; será un "Frankestein", dice Jorge Alcocer", en Sin Embargo, 28 de noviembre de 2013, http:/ / www.sinembargo.mx/28-11-2013/828801 y "Gobernadores se imponen en reforma política”, Milenio Diario, 28 de noviembre de 2013, http:/ /www. milenio.com/politica/Madero-reforma-electoral-Javier-Corral_0_198580233. html

${ }^{71}$ Veáse "Gobernadores pretenden obstruir Pacto por México para reventar reforma electoral: Madero”, en SDPnoticias.com, 14 de junio de 2013. http:/ / www. sdpnoticias.com/nacional/2013/06/14/gobernadores-pretenden-obstruir-pactopor-mexico-para-reventar-reforma-electoral-madero

72 Por ejemplo, Emilio Gamboa Patrón, coordinador de los senadores del PRI, declaró que la versión revisada atendía las demandas de los gobernadores. Veáse “Conceden gusto a gobernadores con INE", Reforma, 5 de noviembre de 2013.

${ }^{73}$ La nueva legislación establece que el INE puede intervenir cuando la situación social en una unidad subnacional dada ponga bajo riesgo la organización de las elecciones locales por el opLE o cuando la intervención de otra rama pudiera afectar a la imparcialidad del ople. Como sostiene Torres Ruiz (op. cit.), se trata de premisas difíciles de demostrar y que abren la puerta a interpretaciones discrecionales. Luis Carlos Ugalde, expresidente del IFE y experto en temas electorales, también sostiene esta opinión. Consúltese "Lo Bueno, Lo Malo y lo incierto de la reforma electoral", en Animal Político, 27 de mayo de 2014. http:/ /www.animalpolitico.com/blogueros-blog-invitado/2014/05/27/lo-bueno-lo-malo-y-lo-incierto-de-la-reforma-electoral/ 
consejos generales del opLE pasarían a ser nombrados (y removidos de sus cargos) directamente por el INE en lugar de por las legislaturas estatales. ${ }^{74} \mathrm{~A}$ pesar de este cambio, la influencia de los gobernadores sobre las instituciones electorales locales no desapareció sino que se convirtió en indirecta: por un lado, son los mandatarios quienes en muchos casos proponen candidatos ante el INE en un intento de propiciar sus preferencias ${ }^{75}$ al tiempo que ejercen cierto poder sobre el aparato administrativo y establecen el presupuesto de los ople (que aún dependen de los recursos de los gobiernos estatales). ${ }^{76}$

\section{CONCLusiones}

En este trabajo hemos abordado un aspecto particular de las políticas de recentralización: la respuesta de los gobernadores a estas iniciativas. Como hemos argumentado, la mayor parte de la bibliografía sobre el tema ha descuidado el asunto asumiendo que, por defecto, los políticos subnacionales se opondrán a cualquier intento en este sentido. Desafiando este supuesto, proporcionamos un marco teórico para entender en qué circunstancias los gobernadores se oponen a la recentralización y bajo qué condiciones permanecen neutrales o incluso apoyan estas políticas. En pocas palabras, los gobernadores tienen diferentes preferencias sobre el tipo de recentralización y estas preferencias son el resultado de cálculos particulares en término de costos y beneficios vinculados al statu

${ }^{74}$ En mayo de 2016 el InE promovió la remoción de los consejeros electorales de Chiapas.

${ }^{75} \mathrm{El}$ proceso de nombrar a los consejeros electorales estatales fue diseñado con la intención de hacer la selección transparente e imparcial. Sin embargo, se denunció que los candidatos que finalmente fueron elegidos por el INE eran en la mayoría de los casos cercanos al PRI (Torres Ruiz, op. cit.).

${ }^{76}$ Entrevista a Jorge Alcocer, experto en asuntos electorales y director de la revista Voz y Voto, Ciudad de México, 22 de marzo de 2014. Respuesta de Irma Méndez de Hoyos a una pregunta formulada por el autor en el marco del seminario "La Reforma Política Desde la perspectiva de los Actores: Motivaciones, alcances y Resultados de cara a las Elecciones de 2015”, Flacso México, 22 de abril 2015. 
quo existente y al escenario posterior a la recentralización. En términos generales, los gobernadores están abiertos a la recentralización administrativa mientras se oponen a la recentralización política. En el caso de recentralización fiscal reaccionan contra una recentralización de los gastos, mientras que favorecen la recentralización de los impuestos. Además, los gobernadores son capaces de expresar abiertamente sus posiciones, sobre todo en aquellos casos en que se descentralizó el sistema político, como es el caso en México desde finales de los años noventa.

El análisis comparativo de los últimos esfuerzos de recentralización administrativa y política en México aporta evidencia para apoyar nuestras conjeturas.

Ciertamente, las razones detrás de las políticas de recentralización eran diferentes. En el ámbito administrativo, el objetivo era mejorar la eficiencia económica y promover la transparencia en el uso de los recursos federales. El principal actor que impulsaba las reformas fue el secretario de Hacienda con la intención de reforzar la capacidad de supervisión del gobierno federal y de limitar la autonomía de las unidades subnacionales en el uso de los recursos transferidos desde el centro. En el ámbito político, el movimiento de centralización más significativo fue promovido por la oposición (en lugar de por el presidente) en un intento de limitar lo que estas fuerzas políticas consideran una intromisión excesiva de los gobernadores del PRI en asuntos electorales.

Como anticipara nuestro argumento, los gobernadores mexicanos reaccionaron activamente contra la recentralización política y fueron capaces de bloquear una propuesta que exigía la eliminación de los institutos estatales electorales, controlados y utilizados por ellos mismos en favor de su partido en muchos de los estados mexicanos. Los organismos electorales estatales reformados, los nuevos opLe, seguirán organizando y controlando las elecciones locales y hay indicios de que los gobernadores todavía ejercen un control indirecto sobre ellos. En contraste, los mandatarios estatales adoptaron una posición diferente cuando se enfrentaron a la recentralización en el ámbito educativo. Como se argumentó, la administración del sistema y la prestación de servicios educativos se habían vuelto difícil en muchos estados del país, 
especialmente en aquellos en donde las secciones locales del sindicato de los docentes eran fuertes y radicales. Como resultado, los gobernadores se mantuvieron indiferentes o incluso apoyaron la recentralización de la nómina y de la evaluación de maestros. La tabla 4 sintetiza la lógica detrás de los posicionamientos.

TABLA 4

Reformas recentralizadoras y posición de los gobernadores

\begin{tabular}{|c|c|c|}
\hline & $\begin{array}{l}\text { Recentralización } \\
\text { administrativa }\end{array}$ & Recentralización Política \\
\hline Beneficios statu quo & $\begin{array}{l}\text { Oferta de servicios valorados } \\
\text { por la ciudadanía }\end{array}$ & $\begin{array}{l}\text { Control de institutos electorales } \\
\text { locales, influencia en las } \\
\text { elecciones. }\end{array}$ \\
\hline Costos statu quo & $\begin{array}{l}\text { Económicos: salarios, } \\
\text { infraestructura } \\
\text { Políticos: negociación con } \\
\text { sindicatos }\end{array}$ & $\begin{array}{l}\text { Acusaciones de injerencia en los } \\
\text { procesos electorales. }\end{array}$ \\
\hline $\begin{array}{l}\text { Beneficios potenciales } \\
\text { de la recentralización }\end{array}$ & $\begin{array}{l}\text { Reducción de costos } \\
\text { económicos y políticos }\end{array}$ & \\
\hline $\begin{array}{l}\text { Costos potenciales de la } \\
\text { recentralización }\end{array}$ & & $\begin{array}{l}\text { Reducción profunda de la } \\
\text { influencia de los gobernadores } \\
\text { a partir de la eliminación de } \\
\text { institutos locales }\end{array}$ \\
\hline $\begin{array}{l}\text { Respuesta a la } \\
\text { recentralización }\end{array}$ & $\begin{array}{l}\text { Apoyo } \\
29 \text { Gobernadores a favor de } \\
\text { la reforma } \\
0 \text { En contra } \\
3 \text { Neutrales }\end{array}$ & $\begin{array}{l}\text { Oposición } \\
3 \text { Gobernadores a favor de la } \\
\text { reforma } \\
14 \text { En contra } \\
3 \text { Neutrales } \\
12 \text { Sin posición clara }\end{array}$ \\
\hline
\end{tabular}

Fuente: Elaboración propia.

Mientras que los años noventa fueron la década de la descentralización en todo el mundo, parece que ahora estamos frente a una tendencia inversa de recentralización, con manifestaciones en países muy disímiles. Estas políticas recentralizadoras deben ser analizadas desde una perspectiva académica y la creciente 
bibliografía sobre el tema parece confirmar la intención de explicar los diferentes aspectos de este nuevo movimiento. Como fue el caso con la descentralización, las políticas de recentralización también están asociadas a las promesas particulares. El tiempo confirmará si estas promesas pueden cumplirse o no, como sucedió en el caso de la descentralización.

\section{Bibliografía}

Ahmad, E., L. Keping, T. Richardson y R. Singh, "Recentralization in China?”, IMF Working Paper WP/02/168, International Monetary Fund, Washington, D. C., 2002.

Álvarez, J., V. García Moreno y H. Anthony Patrinos, Institutional Effects as Determinants of Learning Outcomes: Exploring State Variations in Mexico, Policy Research Working Paper 4286, 2007.

Andere, "Las leyes, la política y la alta política educativa", Cuestiones Constitucionales, núm. 16, enero-junio 2007.

Benton, A. L., "What Makes Strong Federalism Seem Weak? Fiscal Resources and Presidential-Provincial Relations in Argentina", Publius: The Journal of Federalism, vol. 39, núm. 4, 2009, pp. 651-676.

Beer, C., Electoral Competition and Institutional Change in Mexico, Notre Dame, Notre Dame University Press, 2003.

Beramendi, P. y A. Diaz-Cayeros, "Distributive Tensions in Developing Federations", trabajo presentado en la conferencia anual de la American Political Science Association, 2008.

Cejudo, Guillermo, "Los gobernadores y el regreso del PRI", Nexos, agosto de 2012.

Dickovick, T., Decentralization and Recentralization in the Developing World: Comparative Studies from Africa and Latin America, University Park, The Pennsylvania State University Press, 2011.

Dickovick, T., "Recentralization in Latin America: Institutional Layering and Presidential Leverage", trabajo presentado en la conferencia anual de la American Political Science Association, 2011.

Dickovick, T. y K. Eaton, “Latin America's Resurgent Centre: National Government Strategies after Decentralization”, The Journal of Development Studies, vol. 49, núm. 11, 2013, pp. 1453-1466. 
Dragu, T. y J. Rodden, "Representation and Redistribution in Federations", Proceedings of the National Academy of Sciences, vol. 108, núm. 21, 2011, pp. 8601-8604.

Eaton, K., "Political Obstacles to Decentralization in Argentina and the Philippines", trabajo presentado en la Conferencia anual de la American Political Science Association, Boston, 3-6 de septiembre de 1998.

Eaton, K., "The Link between Political and Fiscal Decentralization in South America”, en A. Montero y D. Samuels (eds.), Decentralization and Democracy in Latin America, Notre Dame, Notre Dame University Press, 2004.

Eaton, K., "The Centralism of 'Twenty-First-Century Socialism': Recentralising Politics in Venezuela, Ecuador and Bolivia”, Journal of Latin American Studies, vol. 45, núm. 3, 2013, pp. 421-450.

Eaton, K., "Recentralization and the Left Turn in Latin America: Diverging Outcomes in Bolivia, Ecuador, and Venezuela", Comparative Political Studies, vol. 47, núm. 8, 2014, pp. 1130-1157.

Eaton, K. y T. Dickovick, "The Politics of Re-Centralization in Argentina and Brazil”, Latin American Research Review, vol. 39, núm. 1, 2004, pp. 90-122.

Escobar-Lemmon, M., "Fiscal Decentralization and Federalism in Latin America”, Publius: The Journal of Federalism, vol. 31, núm. 4, 2001, pp. 23-41.

Falleti, T., Decentralization and Subnational Politics in Latin America, Nueva York, Cambridge University Press, 2010.

Fernández, M., "From the Streets to the Classrooms: The Politics of Education Spending in Mexico", tesis doctoral, Duke University, 2012.

Flamand, L., "The New Role of Subnational Governments in the Federal Policy Process: The Case of Democratic Mexico”, en G. O'Donnell, J. Tulchin, A. Varas y A. Stubits (eds.) New Voices in the Study of Democracy in Latin America, Washington D. C., Woodrow Wilson International Center for Scholars, 2008.

Geddes, B., "How the Cases You Choose Affect the Answers You Get?", Political Analysis, vol. 2, núm. 1, 1990, pp. 131-150.

Gel'man, V., "Leviathan's Return: The Politics of Recentralization in Contemporary Russia", en C. Ross y A. Campbell (eds.), Federalism and Local Politics in Russia, Nueva York, Routledge, 2009. 
González, L., "Political Power, Fiscal Crises, and Decentralization in Latin America: Federal Countries in Comparative Perspective (and Some Contrasts with Unitary Cases)", Publius: The Journal of Federalism, vol. 30, núm. 2, 2008, pp. 211-247.

González, L., Presidents, Governors and the Politics of Distribution in Federal Democracies, Nueva York, Routledge, 2016.

Grindle, M., Interests, Institutions, and Reformers: The Politics of Education Decentralization in Mexico, Washington, D. C., Wilson Center, 2002.

Hernández Rodríguez, R., El centro dividido. La nueva autonomía de los gobernadores, México, El Colegio de México, 2008.

Konitzer, A. y S. Wegren, "Federalism and Political Recentralization in the Russian Federation: United Russia as the Party of Power", Publius: The Journal of Federalism, vol. 36, núm. 4, 2006, pp. 503-522.

Langston, J., "Governors and 'Their' Deputies: New Legislative Principals in Mexico", Legislative Studies Quarterly, vol. 35, núm. 2, 2010, pp. 234-258.

López Murcia, J., "The Role of Economic Performance on the Emergence of Recentralization: Colombia, 1994-2014", trabajo presentado en la Conferencia anual de la American Political Science Association, 3-6 de septiembre de 2015.

Méndez de Hoyos, Irma, "Los órganos de administración electoral y la calidad de las elecciones locales en México: un análisis de los institutos electorales locales", en Irma Méndez de Hoyos y Nicolás Loza (coords.), Instituciones electorales, opinión pública y poderes políticos locales en México, México, Flacso, 2013.

Merino, Gustavo, "Federalism and the Policy Process: Using Basic Education as a Test-Case of Descentralization in Mexico", tesis doctoral, Cambridge, Harvard University, 1999.

Merino, M., La transición votada, México, FCE, 2003.

Mizrahi, Yemile, "Democracia, eficiencia y participación: los dilemas de los gobiernos de oposición en México", Política y Gobierno, vol. 2, núm. 2, 1995, pp. 177-205.

, From Martyrdom to Power: The Partido Acción Nacional in Mexico, Notre Dame, University of Notre Dame Press, 2003.

Montero, A. y D. Samuels (eds.), Decentralization and Democracy in Latin America, Notre Dame, Notre Dame University Press, 2004. 
Oi, J., K. Singer Babiarz, L. Zhang, R. Luo y S. Rozelle, "Shifting Fiscal Control to Limit Cadre Power in China's Townships and Villages", The China Quarterly, 211, 2012, pp. 649-675.

O'Neill, K., Decentralizing the State: Elections, Parties, and Local Power in the Andes, Nueva York, Cambridge University Press, 2005.

Olmeda, J., "El péndulo descentralización-recentralización y su aplicación a la reforma educativa en México", Revista de Relaciones Internacionales, Estrategia y Seguridad, vol. 9, núm. 2, 2014, pp. 143-164.

Reddaway, P y R. W. Orttung, The Dynamics of Russian Politics: Putin's Reform of the Federal-Regional Relations, vol. 2, Oxford, Rowman \& Littlefield Publishers, 2005.

Remmer, Karen L. y Erik Wibbels, "The Subnational Politics of Economic Adjustment: Provincial Politics and Fiscal Performance in Argentina”, Comparative Political Studies, vol. 33, núm. 4, 2000, pp. 419-451.

Riker, W., Federalism: Origin, Operation, and Significance, Boston, Little Brown, 1964.

Rodríguez, V., La descentralización en México. De la reforma municipal a Solidaridad y el nuevo federalismo, México, FCE, 1999.

Rosas, Guillermo y Joy Langston, "Gubernatorial Effects on the Voting Behavior of National Legislators”, Journal of Politics, vol. 73, núm. 2, 2011, pp. 477-493.

Ross, C., "Federalism and Electoral Authoritarianism under Putin", Demokratizatsiya: The Journal of Post-Soviet Democratization, vol. 13, núm. 3, 2005, pp. 347-371.

Sharafutdinova, G., "Subnational Governance in Russia: How Putin Changed the Contract with His Agents and the Problems It Created for Medvedev", Publius: The Journal of Federalism, vol. 40, núm. 4, 2009, pp. 672-696.

Sharafutdinova, G., "Gestalt Switch in Russian Federalism? The Decline in Regional Power under Putin", Comparative Politics, vol. 5, núm. 3, 2013, pp. 357-376.

Tavares de Almeida, M., "Recentralizando a federação?", Revista de Sociologia e Política, núm. 24, 2005, pp. 29-40.

Torres Ruiz, R., "México y su nueva reforma político electoral", Revista Mexicana de Estudios Electorales, núm. 4, 2014, pp. 119-159. 
Wibbels, E., Federalism and the Market: Intergovernmental Conflict and Economic Reform in the Developing World, Cambridge y Nueva York, Cambridge University Press, 2005.

Willis, E., C. Garman y S. Haggard, "The Politics of Decentralization in Latin America”, Latin American Research Review, vol. 34, núm. 1, 1999, pp. 7-56. 